This is the final peer-reviewed accepted manuscript of:

Olivia Levrini, Mariana Levin, Paola Fantini, Giulia Tasquier, Orchestration of classroom discussions that foster appropriation (2018), Science Education, Volume 103 , Issue 1, Pages 206-235.

The final published version is available at: https://doi.org/10.1002/sce.21475

Rights / License:

The terms and conditions for the reuse of this version of the manuscript are specified in the publishing policy. For all terms of use and more information see the publisher's website. 


\title{
Orchestration of classroom discussions that foster appropriation
}

\author{
Levrini Olivia ${ }^{1}$, Levin Mariana ${ }^{2}$, Fantini Paola ${ }^{3}$, Tasquier Giulia ${ }^{1}$ \\ ${ }^{I}$ Department of Physics and Astronomy, Alma Mater Studiorum - University of Bologna, Italy \\ ${ }^{2}$ Department of Mathematics, Western Michigan University, Kalamazoo, United States \\ ${ }^{3}$ Liceo Scientifico “A. Einstein”, Rimini, Italy
}

Abstract: This paper investigates how features of teaching practice may foster appropriation: learning that involves both deep conceptual understanding and transforming scientific discourse in a way that is significant for oneself.

Data were drawn from classroom discussions during a unit on thermodynamics that took place in a high school in Italy. We analyze a specific metaphor "tightening the reins and letting them loosen" used by the teacher to characterize her practice. By contrasting episodes of classroom discussion in terms of talk moves and participant frameworks, we discovered that behind the metaphor was a complex epistemological scaffolding that the teacher enacted across her lessons. This scaffolding was articulated across four moments of discussion, each with a different function and purpose: Sharing the construction of a collective disciplinary narrative; Elaborating the narrative in epistemological terms by articulating criteria for comparing different approaches to the disciplinary content; Analyzing the comparison criteria to test and characterize their coherence and inner consistency; and Situating oneself with respect to different approaches to the content informed by the refined criteria (SEAS). We argue that these functions provided the scaffolding for physics to be a context for 
both disciplinary learning and students' search for personal relevance and meaning.

Keywords: Classroom discourse, appropriation, Bakhtin, thermodynamics

\section{Introduction}

Research has indisputably pointed out a worldwide crisis in science education: school students perceive science as "irrelevant" (Osborne \& Dillon, 2008). One of the unwanted consequences of this is the decreasing interest of students in pursuing careers related to science and technology (Rocard et al., 2007). At the same time, since science and technology permeate virtually all aspects of society, science education needs to prepare all citizens with scientific literacy (Roberts, 2007) including skills necessary to make reasoned decisions concerning personal, social and global issues related to science and technology. Thus, scientific literacy remains an important goal for all students, regardless of their career choices.

At a broad level, two directions can be followed to address the quest to "make science relevant." One possible direction is to situate science content in topics that students may care about (e.g., art, sport, global warming or other socio-scientific issues). The second involves engaging students in learning environments designed to engender a multi-faceted and rich view of the subject matter that leverages students' personal tastes and interests. While this first approach seems much more appealing than the second one, in the mathematics education literature, Sinclair warns about the possible implications of that approach to making disciplinary content relevant to students (Sinclair, 2001). She argues that while engaging students with mathematics that has, for example, artistic connections can pique students' interest and stimulate their aesthetic sense, it can send an 
insidious meta-message - that mathematics is an aesthetically sterile domain whose aesthetic potentialities can only be accessed through engagement with other domains of interest. She writes

We count on students' sensitivities and attractions to the arts to help them appreciate mathematics. But could we understand what these sensitivities are and why these attractions exist in content that are themselves in mathematics? In other words, could we reverse the direction or the aesthetic flow, so it originates in the mathematics? (Sinclair, 2001, p. 25).

This article, following the challenge of Sinclair, aims to unpack the conditions around students engaging in personally meaningful and relevant ways with formal physics content within a school disciplinary context. That is, we explore a case of teaching practice where the discipline of physics, as it was treated in class, became a locus that was able to resonate with or to stimulate an aesthetic form of engagement.

Our argument is organized as follows. In the next section we introduce and discuss the concept of appropriation to illustrate cases of personal relevance that students attach to physics in engaging with formal disciplinary contents (thermodynamics, in this case); this description opens the stage for the focus of the paper, that is the kind of teaching that fostered that type of engagement. In order to frame the analysis theoretically, section three includes the review of the research literature on classroom discourse we used to orient the analysis. Finally we report the empirical study by articulating its presentation in terms of context of the implementation, data sources and methods, analysis and findings, and discussion and conclusions. 


\section{Background: operationalizing "meaningful" learning - appropriation}

In previous work we identified a kind of deep and meaningful learning in which students

made the content of class discussions personally relevant. We termed this type of learning appropriation (Levrini et al., 2015) and, through an analytic process of

operationalization, we argued that appropriation involves learning science in a way that is deeply integrated into students' personal construction of their sense of self (Levrini et al., 2018).

The construct of appropriation was inspired by the work of Vygotsky, 1978, Rogoff, 1995, and Bakhtin, 1981. In the words of Bakhtin, appropriation is defined as follows:

It [a word] becomes 'one's own' only when the speaker populates it with his own intentions, his own accent, when he appropriates the word, adapting it to his own semantic and expressive intention. Prior to appropriation, the word $[\ldots]$ exists in other people's mouths, in other people's contexts, serving other people's intentions: it is from there that one must take the word, and make it one's own. (Bakhtin 1981, pp.293-4)

The essence of the Bakhtinian notion of appropriation is that individuals create meaning for objects of knowledge through encountering others' discourse about them, negotiating and reconciling others' ways of understanding and then coming to use the constructs with one's own inflections and nuances. In this sense, learning needs a polyphony of others' voices to be appropriated where "such voices act as voices belonging to real people with whom an imaginary dialogue can be conducted beyond time and space" (Boero et al., 
1997). Then, when appropriation occurs, one's discourse reflects one's own voice. ${ }^{1}$

Over the course of conducting the end of unit interviews in our study (Levrini et al., 2015), a phenomenon that we began perceiving during our observations of the unit became increasingly evident: most of the students seemed to have found personal routes for making sense of the content of the unit. The way they spoke about the content was sophisticated from a disciplinary perspective, but also infused with authentic terms and expressions that revealed their unique voices. When asked in the interviews to discuss specific concepts like temperature, the students did not repeat the definition of temperature provided by the teacher or textbook. Instead, they focused their attention on different pieces of knowledge related to temperature and reassembled those knowledge pieces in accordance with, what we eventually called, idiosyncratic "signature" ideas. The discourse of most of the students revealed also an interesting self-confidence with the discipline and with their position within the dynamics of classroom discussions. That is, the students appeared emotionally engaged with thermodynamics in a passionate, but positive, way. It is because of this interweaving of intellectual, emotional and social nuances in students' voices that we felt the need to capture this kind of deep and affective personal engagement in learning physics (Levrini et al., 2015; Levrini et al., 2018).

Before turning to the main analysis of the current paper in which we unpack the aspects of a teaching practice that are conjectured to be relevant for appropriation, we first offer the reader an exemplification of the construct of appropriation itself. Towards

\footnotetext{
${ }^{1}$ Bakhtin's notion of appropriation is intrinsically related to his constructs of voice and polyphony that have been inspirational also for science and mathematics education researchers (e.g. Bartolini Bussi, 1995; Boero, Pedemonte, \& Robotti, 1997; Delgatto, 2011).
} 
this end, we present the cases of Matteo and Michele (pseudonyms), two students in a high school physics class with interestingly personal (and contrasting) ways of experiencing the learning of thermodynamics.

Matteo's end of unit interview was rich with words like philosophy, speculation, reflections, reasoning, being and becoming, which did not characterize either the teacher's discourse or the discourse of other students. Building upon this evidence we recognized an idiosyncratic "signature" idea in his description of what he liked most within his study of thermodynamics (the arrow of time in the discussion of entropy): the philosophical distinction between "being" and "becoming." This idea was, for him, a gateway for accessing the disciplinary content of the unit and making sense of them. Indeed, when he was interviewed about the concept of temperature, Matteo focused his attention on two learned laws in which temperature appears: the ideal gas law $(\mathrm{PV}=\mathrm{nRT})$ and the law of calorimetry $(\mathrm{Q}=\mathrm{mc} \Delta \mathrm{T})$. This comparison allowed him to stress the dual property of temperature, being a quantity that describes an equilibrium state or being a cause for a process. It is in this distinction between state and process that Matteo could recognize a connection with the philosophical notions of being (state) and becoming (process/change). Indeed, Matteo saw in the law of calorimetry $(\mathrm{Q}=\mathrm{mc} \Delta \mathrm{T})$ an expression of becoming: "there is a change [because of $\Delta T$ ] that means everything is not stable and everything is not being, there is something that changes. ” In the Ideal Gas Law $(\mathrm{PV}=\mathrm{nRT})$ he instead saw an expression of being: "[There is] absolute temperature $T$, that doesn't change. There is not $\Delta$ [difference in temperature], there is not the change...." In classroom activities prior to the interview, Matteo had showed a strong interest in the distinction between being and becoming. In this sense this signature idea 
appeared very authentic, non-incidental and particularly relevant for him. It moreover was consistent with his personal view of physics. Because of his epistemological interests, Matteo became positioned socially as the person who defended the role of speculations - "the philosopher" - within the class.

In contrast, the idiosyncratic "signature" idea that the discourse of another student, Michele, revolved around can be recognized in a sentence from the end of unit interview in which he explicitly states: "I like Physics because it explains how reality works. That is to say, I'm very curious about how objects work and about natural events...." Michele had a strong interest in engines, real objects, and "how things work." He repeated these words several times during the interview and throughout the entire unit on thermodynamics. When asked about the concept of temperature, Michele focused his attention on a special piece of knowledge related to temperature: the temperature gradient, because this is what makes engines work. Indeed, what he found particularly important about the concept of temperature is that "Different temperatures are necessary ... only with different bodies with different temperatures can we have a cycle and work; different temperatures induce a heat exchange - as we call it - and the heat exchange induces work; heat is turned into work." Also in the case of Michele, his personal position was consistent with a specific view of physics, where the role of technological applications and mechanical models was central. In contrast to Matteo, Michele felt philosophical reflections were useless and boring. His defense of this position in front of his classmates led him to become positioned socially within the class as "the engineer." Thus, Matteo and Michele, in selecting and reassembling pieces of knowledge, in the words of Bakhtin, populated a disciplinary word (temperature) with personal intentions 
and purposes. This personal engagement with the content allows them to find a recognized role in the dynamics of classroom discussions in which they appeared confident.

Michele and Matteo provide examples of the kind of learning that took place in this classroom. This learning shows to what extent content fidelity and personal relevance was resolved at the level of students' discourse: that indeed revealed both mastery of disciplinary contents and personal inflections. Because of the productivity of the case, we next moved to asking ourselves about the kind of learning environment and teaching practice that set the context for such productive learning to take place. Thus, our primary research question of the present study became:

What general features of the interactions between a teacher and students can be recognized in a context in which students have been observed to appropriate the material they are learning? What aspects of teaching practice can be reasonably argued to have facilitated students in finding their voices within classroom activities on thermodynamics?

\section{Theoretical framework}

Our analysis is framed within the literature on classroom discourse that we selected to unpack the interactions between the teacher and the students. In this class, whole class discussions were common. Accordingly, the literature we used to frame our analyses mainly concerns studies on patterns of interaction that a teacher can set-up at the level of the whole class, as well as productive talk moves used by the teacher in interacting with 
individual students during whole class discussions.

\section{Participant Frameworks}

Several studies have investigated classroom interactions in terms of participation structures so as to point out both how teachers manage the whole class, and to understand what can foster deep subject matter learning among students (Erickson, 1986; Lampert, 1990; Lemke, 1990). For our analysis the notion of participant framework (Goffman, 1974; 1981) has been of special interest. Participant frameworks show the set up of the scenario where interactions take place by describing the rights, roles, and responsibilities of participants in a setting with respect to the issue of "Who can speak what and when?" (Hegedus \& Penuel, 2008.

Tabak and Baumgartner (2004) studied the features of a range of participant frameworks (e.g., teacher as monitor, teacher as mentor, and teacher as partner), describing them in high school biology classrooms in terms of "asymmetry or symmetry in teacher-student relationships, the discourse pattern, and the explicit or implicit nature of instruction" (Tabak and Baumgartner, 2004, p. 403). We describe each of these participant frameworks briefly below.

The "teacher as monitor" participant structure is characterized by an asymmetrical relationship, an Initiate-Respond discourse pattern, sometimes followed by Feedback (I$\mathrm{R}-[\mathrm{F}])$ and the nature of instruction is explicit: the teacher asks about procedures, tasks and completion of task-related milestones. The "teacher as mentor" participant structure is still characterized by an asymmetrical relationship and by an I-R-F pattern. Instruction is also explicit, but unlike in the monitor framework, I-R-F leaves "room for 
interpretation, negotiation, and adaptation of ideas, rather than the testing and evaluation (E) found in typical recitation I-R-E patterns" (Tabak \& Baumgartner, 2004, p. 403). In this participant structure, "the teacher tries to help the students to align their thinking and actions with scientific norms without dictating actions or explanations" (Tabak \& Baumgartner, 2004, p. 403). The "teacher as partner" participant framework is similar to the teacher as mentor framework, but here the teacher assumes a different posture: "the teacher presents herself as a peer" and "joins the group for a few minutes and takes part in their investigation as a genuine member of the group" (Tabak \& Baumgartner, 2004, p. 403). In "teacher as partner" the teacher is no longer the sole authority and multiple students are authorized to speak. In their paper, Tabak and Baumgartner focused on the analysis of the "teacher as partner" participant framework to support inquiry-based science education.

For our purposes, their work is important for at least two general and methodological reasons. Firstly, their work of modeling teacher-student relationships in terms of participant frameworks allowed them to analyze the explicit or implicit nature of instruction. In our work, we use participant frameworks to describe the type of interactions within the class and the different roles and responsibilities that the teacher and students have over the course of two lessons. Secondly, their work, like ours, zoomed in on students' processes of appropriation and pointed out that it is the tension between what Bakhtin calls "authoritative discourse" and "internally persuasive discourse" that triggers processes of appropriation in individuals. Authoritative discourse, if seen from the perspective of the student, is monologic: it must be taken as it is without any possibility of negotiation. On the contrary, internally persuasive discourse can occur 
if there is reciprocity in classroom talks, a supportive attitude and an environment where a person interacts with the collective discourse (the discourse of the others) and is encouraged to transform it into a personal discourse by infusing personal meaning to others' words. Both of them play a role and it is their tension that allows students' discourse to be personal, while respecting scientific constraints. As Tabak and Baumgartner write:

This tension [between "authoritative discourse" and "internally persuasive discourse"] opens new possibilities for students' ways of being in relation to others, those that represent the power of the institution of schooling and of science, but it also constrains their words and their actions by virtue of this power they represent. [...] It is these issues of differentiation and identification, alterity (otherness) in Bakthtian terms $[\ldots]$, that lie at the nexus of the two pairs of distinctions that we have presented - authoritative and internally persuasive discourse and mastery and appropriation - and their relation to processes of identity formation. (Tabak \& Baumgartner, 2004, p. 31)

\section{Productive Talk Moves}

Within the literature on classroom talk moves, the most familiar structure, and probably the most-studied one, is the Initiate, Respond, and Evaluate (IRE) sequence (Mehan, 1979; Candela, 1999) or its variant, the Initiate, Respond and Feedback/Follow up (IRF) sequence. In their cross-national study of teaching practices, the IRE/IRF discourse pattern has been identified as typical of many classrooms around the world (Stigler \& Hiebert, 1999) and it is the talk structure that leads also to the "teacher as monitor" 
participant framework in classrooms. In analyses of classroom discourse, the presence of IRE/IRF sequences has commonly been used to argue that the classroom environment operates according to a monologic stance in which ideas are supposed to remain fixed as they are transmitted from teachers to students (Wells, 2007). In this sense, such classroom environments do not foster individual processes of searching for personal relevance. Furthermore, the triadic structure of IRE/IRF mirrors an asymmetric relationship of power that the teacher realizes through the use of "known-information questions" (Wells, 2007). Sayavedra (2018) complexifies this perspective on IRE, demonstrating that, in responsive classrooms, when used with open talk structures such as student presentations, IRE sequences can help elaborate and refine student ideas while positioning students as the owners of the mathematical ideas.

An interesting approach to IRE/IRF has been suggested by O'Connor and Michaels (e.g. O'Connor \& Michaels, 2007). They introduced the lens of "ideological stance" and, by using this lens, they problematize the common identification of a formal lecture or IRE/IRF with monologic discourse:

It is not difficult to find examples where the two senses are not isomorphic: a formal lecture, with one person speaking and no direct questions, is interactionally and linguistically positioned at the monologic end of the continuum. However, ideologically, it may be couched within a setting in which groups of listeners may question, challenge, and eventually respond, rendering the lecture part of an activity system that is inherently Dialogic ${ }^{2}$ in its ideological stance. Conversely, it is easy to

\footnotetext{
${ }^{2}$ The capital letter is used by O'Connor \& Michaels to indicate when Monologic or Dialogic are used to indicate the ideological stance of discourse.
} 
find examples of 'dialogue,' where a teacher asks a question, a student responds, and the teacher follows up, that are nevertheless inherently monologic in terms of the teacher's stance. (O'Connor \& Michaels, 2007, p. 277).

The flow of argument in the 2007 paper leads O'Connor and Michaels to discuss a variant of IRE: Initiation-Response-Revoicing (I-R-R) sequence. Revoicing involves attending to the ideas and words of students and repeating or restating them. The construct of revoicing was introduced (e.g., O'Connor \& Michaels, 1996) as a productive talk move used by teachers to redistribute authority in the classroom: through revoicing, students are positioned in such a way as to be able to accept, decline or modify the teacher's attributions. Further, the purposes of revoicing are varied, ranging from animating student contributions by making them more precise or elaborate to clarifying or contextualizing students' ideas (diSessa, Greeno, Michaels \& O’Connor, 2016; Forman \& Ansell, 2002; Russ, Sherin \& Lee, 2016). According to this conceptualization, the triadic Initiation-Response-Revoicing structure introduces a significant change with respect to IRE, since through revoicing "the student is positioned as a thinker or theorizer, the holder of a noteworthy idea, theory, or explanation" (O'Connor \& Michaels, 2007).

In the light of the previous literature, our general research question has now been transformed into a set of more technical sub-questions: 
What participant frameworks and productive talk moves can be recognized in a context where students have been observed to appropriate the material they are learning? What teacher-student relationships, discourse patterns, and nature of instruction are observed? How can such structures allow students to align their search for personal relevance, their personal thinking, with scientific norms and the content constraints of thermodynamics?

To anticipate, the constructs of talk moves and participant frameworks will allow us to interpret the teachers' practice in interactional terms. Using them, we will trace a number of consequential re-positionings of the teacher with respect to the students throughout the focal lessons. However, we will argue that while such a level is fundamental, it is not enough to interpret appropriation: what we discovered to be crucially important are the epistemological purposes and functions of the discussions that each of those repositionings served.

\section{Context of implementation}

\subsection{School context of the implementation}

The analysis in this paper is based on a data corpus that comes from a class of 20 students ( $\sim 17$ years old) in a scientifically-oriented high school in Rimini, Italy. An innovative teaching/learning experience on thermodynamics was implemented in this class (see Levrini et al., 2014a for an in depth description of the design).

The school in which the study took place is one of the three public scientificallyoriented Licei (high schools) of the area, attended by students who lived in the neighborhood local to the school. This type of school, being public, is not selective from a social and economical point of view but, even though the range of family professions is 
rather large (from people involved in tourism to physicians and engineers), the majority of the families had a relatively high level of education (secondary school or university degree). The students in the school learn physics through the five years of upper secondary school (grades 9-13). During the first two years, teachers guide knowledge construction by focusing on phenomenological descriptions and laboratory activities of natural phenomena and physical concepts with regard to motion, heat, light and vision, and waves. In the final three years (grades 11-13), the main goals of the curriculum are to reorganize and systematize what students have learned from their laboratory studies in terms of physical theories (mechanics, optics, thermodynamics, electromagnetism, relativity and quantum physics).

However, the most distinguishing feature of this context is not any sort of preselection of the student body nor a program of the school, but rather, a group of teachers, who closely collaborate with the research group in physics education of the University of Bologna. Since 2000, these teachers have regularly attended research seminars and meetings at University of Bologna and they have worked together to co-design interventions to test in their classes. The interventions are often studied by Masters or $\mathrm{PhD}$ students at University of Bologna, as well as by university researchers, when possible. Examples of other experimental interventions have centered around the topics of thermodynamics, quantum physics, relativity, climate change and optics (See Levrini et al., 2014b; Levrini \& Fantini, 2013; Tasquier et al., 2016; Authors et al., 2017) for examples of analyses coming from this work). Since September 2016, the school under study in this paper, is partner of a European Project coordinated by the research group in Physics Education of the University of Bologna (website removed for review). 
Because of this close collaboration, the teachers of this school plan and cover the official curriculum in a coordinated and longitudinal way, engaging students in reflective activities and introducing the epistemological dimension of physics learning. The teacher of the class in the current investigation (PF) co-designed the teaching/learning path that includes the unit on thermodynamics. Furthermore, she was familiar with the students, having taught them physics since the second year of upper secondary school through the time of the study (fourth year). Thus, the students were well-acquainted with both her and her teaching style.

\subsection{Design of the Materials}

The instructional materials used in the present study were the result of the collaborative process described in the previous section (Levrini et al., 2014a). The process led the disciplinary content to be "educationally reconstructed" (Kattmann, Duit, Gropengießer \& Komorek, 1996) according to particular design criteria (described below). Specifically, the content was reconstructed so as to build upon some of the main results in physics education research on teaching/learning of thermodynamics (e.g. Rozier \& Viennot, 1991; Kautz, Heron, Loverude \& McDermott, 2005a; 2005b; Malgieri, Onorato, Valentini \& DeAmbrosis, 2016; Fazio, Battaglia \& Di Paola, 2013), while also respecting broader design principles of longitudinality, multi-perspectiveness and multidimensionality (Levrini et al., 2014a). We describe each of these principles in turn below.

The design principle of longitudinality involves organizing the way concepts are developed in the curriculum so as to draw on unifying themes (crosscutting concepts) that "thread" through the curriculum, like, for example, models and modeling (Tasquier et al., 
2016). In the case of the thermodynamics unit, the students were progressively guided in developing a vocabulary and arguments for comparing thermodynamic approaches to modeling systems, processes, and interactions with the models used in the theories previously studied by the students (classical mechanics and special relativity). The aim was to lead them to become deeply acquainted with the analogical meaning of physical models, like point-mass and ideal fluid, when they are used in contexts like thermodynamics.

For the scope of the following analysis, the design principles of multiperspectiveness and multi-dimensionality deserve a more precise description since, we will argue, some details of their implementation played a fundamental role in the classroom dynamics. According to multi-perspectiveness, students were given the opportunity to analyze the same content from two different perspectives. In the case of the thermodynamics unit, students learned the content from both a macroscopic and the microscopic perspective. The two perspectives were introduced and analyzed according to the principle of multi-dimensionality, in the sense that they were explored and explicitly compared along many different dimensions: for their conceptual, experimental, and formal implications as well as, and in a particular way, for their philosophicalepistemological features.

Concretely, the principle of multidimensionality was enacted in this unit through specific activities (an open-ended take-home questionnaire and collective discussions around it) aimed at equipping students with philosophical words and concepts necessary for framing the comparison between the macroscopic and microscopic approach within Einstein's epistemological distinction between "theories of principles" and "constructive 
theories" (Einstein, 1919). For example, the students were provided with a popular text of Einstein, and texts of two other authors, Poincaré and Drago, that concerned physical knowledge organization in terms of theories. Students were given an opportunity to analyze the texts first individually and then to discuss their analysis collectively. In order to orient students to the analysis of the texts and discussion, they were asked to provide written answers to a questionnaire, organized in two parts: a) An author by author analysis (e.g., In your opinion, what terms or expressions are crucial for characterizing the kinds of theories described by each of the authors? Are there terms or expressions they used that were unclear or ambiguous to you?); b) Comparative analysis (e.g., Do you see common aspects in the texts of the three authors? If so, how would you describe them? Do you see significant differences between the positions of the authors? If so, how would you describe them?). Students were asked to answer these questions as homework. A few days later, students engaged in a collective discussion based on their work with the questionnaires. A similar discussion occurred also at the end of the unit.

The design choices of multi-perspectiveness and multi-dimensionality were motivated primarily by a broader goal of challenging an image of science in which a single "normative" point of view is privileged. The rationale was that by observing the legitimacy of a variety of experts' perspectives and voices (Boero et al., 1997), students could experience Bakhtin's polyphony and gain access to the content of their course in a way that can resonate with diverse intellectual interests and personal tastes. Learning experiences designed from the view of multi-perspectiveness and multi-dimensionality also challenge the rigid (and typical) notion of what constitutes an adequate scientific explanation. Instead of concluding discussions in the name of a naïve idea of absolute 
truth and objectivity, "what a physics explanation explains to me" instead becomes a topic of reflection and discussion.

We will revisit in the discussion of the results the issue of the interrelation between these kinds of materials and how the teacher established and managed a complex combination of participant frameworks.

\section{Data sources and method}

The data corpus we had access to for analysis included: written tasks (quantitative and qualitative problems on key concepts); audio-recordings of most of the lessons; field notes from class sessions in the unit; a questionnaire on epistemological issues; audio recordings of the two focal classroom discussions about the issues addressed in the questionnaire; 8 audio-recorded individual interviews ${ }^{3}$; audio-recorded interview with the teacher; audio-recording of discussions with the teacher about specific points. These data sources were collected in order to give us a window into multiple dimensions of students' experience in the learning environment (i.e. individual conceptual understanding, epistemological and metacognitive competences, reasoning behind teacher moves). In this analysis, the primary data considered were the audio-recordings of the lessons; audio-recording of the two classroom discussions about the issues addressed in the questionnaire; the field notes; the recorded data from teacher's interview and our discussion with her.

The starting point for examining the role of the teacher in orchestrating class discussions was the post-unit interview with the teacher. In this interview, she used the

\footnotetext{
${ }^{3}$ We interviewed 10 students (half of the class), but 2 interviews could not be considered in the analysis since we were not able to complete them, because of external constraints.
} 
common Italian expression "tirare e mollare la corda" (literally, "Tightening the rope (reins) and letting it (them) loosen") to characterize her teaching and how she orchestrated the class dynamics:

"When I am in class, this is probably what I note the most: the tempo of the class. I feel students need both moments where they have to stay [together] all on task and in these moments I accelerate: I go fast and they have to follow me. There are also moments where they have to take their time to play freely with their ideas. If I have to describe my teaching in few words, I would use this expression: 'tirare e mollare la corda.' I learned this over many years of teaching and I think that to give students' learning a rhythm is one of the most important things I try to do" (PF, teacher interview).

We took up this metaphor because it captured a central concern of hers and we conjectured that the teacher's use of "tirare e mollare la corda" was an evocative way to stress a special relation between individual students with their special and personal ways of learning and the class as a whole (as is fundamental for "appropriation", as operationalized in Levrini et al., 2015).

We decided to plan our analysis in two stages.

The first stage was designed to elucidate what the teacher meant by the metaphor through a systematical analysis of the transcripts of lessons that she considered typical of "tightening the reins" and "letting the reins loosen." More specifically the goal of this first stage was to interpret the metaphor in terms of structural features of the interactions in class - who was interacting with whom and for how long-and, hence, in terms of participant frameworks (Hegedus \& Penuel, 2008; Tabak and Baumgartner, 2004). The 
second stage aimed to highlight the way discourse at the level of the whole class could support individual students as they participate in the discussions.

For our analysis, in collaboration with the teacher, we selected two contrasting lessons -- one in which the teacher characterized the dynamic as emblematic of "tightening the reins" (Lesson A) and one in which the lesson was more evocative of what she meant by "letting them loosen" (Lesson B).

Lesson A was a synthetic collective discussion about the major aspects of the macroscopic approach to the second law of thermodynamics, focusing on topics that were very close to the disciplinary content the students had been explicitly studying. For example, a particular topic discussed in lesson A was Clausius' and Kelvin's statements of the second law and the connection of the latter with the Carnot's theorem about efficiency $(\eta<1)$. Lesson A came almost at the end of the unit and the purpose of the discussion was to synthesize, as a class, what had been learned about the second law of thermodynamics from a macroscopic perspective so as to check if the class was ready to re-consider the microscopic perspective and deepen Boltzmann's statistical interpretation of entropy.

In contrast, Lesson B was an open and reflective discussion concerning issues related to epistemological texts (authored by Einstein and others) on methodological distinctions between macroscopic and microscopic approaches to building theories (e.g., Einstein's distinction between "constructive theories" and "theories of principles"). The design principles of multi-perspectiveness, multi-dimensionality, and longitudinality (described in section 4.2) explicitly oriented the classroom activities in Lesson B. Lesson B occurred after the class dealt with the microscopic perspectives (a few days after lesson 
A). Lesson B involved a discussion of passages from the writing of prominent physicists that focused on epistemological issues that the students had considered at the beginning of the unit on thermodynamics through the individual analysis (for homework - on the epistemological questionnaire described in the design section) and collective activities (an earlier class discussion).

For the second stage of our analysis, two contrasting individual cases have been selected: Chiara and Matteo. Chiara and Matteo were among the eight focal students whose end of unit interviews were deeply analyzed in Levrini et al., 2015. We chose to analyze the classroom discourse around these two students since, during the two lessons we considered, they were at the same stage in the appropriation process (in the sense that they both had already found different personal routes into physics and their voices were strongly recognizable). However, they are interesting contrastive cases because of their

profoundly different relationship with physics and with the teacher. Indeed, while Chiara had a strong interest in physics, Matteo appeared to have conflicted emotional engagement with physics. Chiara was very autonomous in learning and systematically reached a competent level, while, according to the teacher, Matteo struggled to reach a sufficient level and the teacher reported paying special attention to Matteo in order to keep him in tune with collective discussions.

\section{Analysis and findings}

The first analysis we present here was aimed at uncovering the broad features of the guiding metaphor of "tightening the reins and letting them loosen." 


\subsection{Empirically Grounding the Orchestration Metaphor "Tightening the Reins and Letting them Loosen"}

\subsubsection{Constructing participant interaction maps}

In order to interpret teacher's words, our first move was to find a way to transcribe the two lessons so as to capture the rhythm of the discussion that the teacher reported to be crucial. For this purpose, "maps" of the lessons were created by recording who was speaking and for how long (in 2 second increments). The maps (figure 1-4) show the participants in the discussion along the y-axis and amount of time each participant had the floor at a given time along the $\mathrm{x}$-axis. Lesson $\mathrm{A}$ is represented in one map. Because lesson B was longer, the entire lesson was divided into three maps that illustrate three different phases of the lesson. Among the speakers we highlight the 8 students that we interviewed at the end of the unit and that we considered for appropriation (Levrini et al., 2015). The cases considered here in our analysis, Chiara and Matteo, are among them. The teacher, who took part in the analysis, provided line-by-line reflective notes on the transcripts of the class discussions that were analyzed (Fantini, 2014).

The four maps are meant to give a top-level visual description of the distribution of talk and to make visible some structural aspects of the interaction that, one can conjecture, characterize the lessons in terms of the kind of participant frameworks they induce. The actual content of the discussion and the actors will be made explicit in detailed analyses of excerpts (staring from the next section, 6.1.2).

[INSERT FIGURE 1 HERE] 
Figure 1. Interactional pattern in lesson A. The duration of each unit is 2 seconds.

The map for lesson A (Fig. 1) shows that it is the teacher (in red at the bottom of the figure) who drives the lesson. The rapidity of exchanges (no moments of silence) can be related to what the teacher said about "tightening the reins" and, in particular, as an indicator that the students are following the discussion closely and ready to participate as soon as given the opportunity. There are also extended exchanges within this lesson where the teacher stays with a single student over several turns. In summary, the interactions in Lesson A are primarily between the teacher and the student with the teacher playing a strong role in driving the discussion.

[INSERT FIGURE 2 HERE]

Figure 2. First interactional pattern in lesson B. The duration of each unit is 2 seconds.

The first part of lesson B (Fig. 2) appears similar to lesson A. The interaction is teacherstudent and individual students take part in the discussion. There are, however, moments of silence and students' contributions are generally longer than in lesson A. This structural aspect, as we will discuss more fully below in the individual level analysis in the next section (in the case of Chiara), is a signal that the dynamics are more studentcentered than in lesson A. Here, as well as in the other segments of Lesson B, the researcher, OL, is also seen to contribute to the discussion. She is positioned as an interested outsider with some ongoing knowledge of the unit and the students through her 
work with the teacher and the class. She did not contribute new ideas to the discussion, asking only clarifying questions and providing comments on what she observed.

\section{[INSERT FIGURE 3 HERE]}

Figure 3. Second interactional pattern in lesson B. The duration of each unit is 2 seconds.

The second part of lesson B (Fig. 3) shows a different interactional pattern. The turns at talk are more similarly distributed between the teacher and the students, with the students providing short contributions to the collective discussion.

\section{[INSERT FIGURE 4 HERE]}

Figure 4. Third interactional pattern in lesson B. The duration of each unit is 2 seconds.

Finally, in the last part of lesson B, there are substantially more student-student interactions. Also here, like in the other parts of lesson B, there are sometimes substantial moments of silence in several places.

As already stressed, the participant interaction maps only give a top-level visual description of the distribution of talk (by whom and how long) during the lessons analyzed. In order to interpret the structural features of the discussion and understand the kind of participant frameworks that were induced in the class, a more detailed analysis including the actual content of the discussion was needed. 
To move the first phase of our analysis to a more refined level, we considered the specific topics under discussion and the nature of the questions posed by the teacher to particular students in order to understand whether (and how) the content of the talk and the types of questions supported the emergence of different participant frameworks (Hegedus \& Penuel, 2008).

Lesson A, due to its nature (a synthesis lesson at the end of the unit), concerns the co-construction of the reasoning that follows from the two statements of the second law of thermodynamics by Clausius and Kelvin, the connection of the latter with the Carnot's theorem about efficiency $(\eta<1)$ and, finally, to the introduction of entropy. The lesson begins with the teacher that points out the sense the collective task, by formulating a specific request:

Teacher: Let's take up the discussion again [about the second principle that they were addressed in the previous lessons]. You speak. Try to make me understand what we have understood about all of this.

We see above that, in just a few words, the teacher moves to establish roles and accountability for the discussion, as well as expressing the scope of the lesson in terms of co-constructing a shared understanding of the material they had discussed thus far. In particular, in establishing roles and accountability, the teacher uses a careful choice of pronouns. Her first words "Let us take up the discussion" imply that the entire class, as a community, is involved in a collective discussion. In this discussion, however, it is the students - "you" - that have to take the stage and "speak" (not the teacher). The teacher then shares the goal of the lesson: "Try to make me understand what we have understood about all of this." In this collective task, the students are supposed to share what the entire 
class (teacher included) has understood, while the teacher is a special audience ("make me understand"). This last move is very subtle since it reverses the usual relationship between teacher and students: the locus of the knowledge is on the students while the teacher is the person who has to understand.

In this collective discussion, the teacher explicitly involves individual students in order to check their knowledge and confidence with the topic. The questions she asks do have right/wrong answers. Yet the discourse pattern is notable in the sense that the questions are posed in the following way: the teacher initiates a statement, then suspends her voice partway through her statements, implicitly asks the student to continue. For example:

Teacher: We have seen that from here [from the second law] comes thermal machines and that the efficiency...

Matteo: The efficiency in a cycle cannot be greater than 1, but... However, this is also in an ideal cycle.

As soon as the student stops talking, the teacher takes the reins again through the strategy of revoicing:

Teacher: Good. It cannot be. We are considering an ideal cycle, an ideal, reversible cycle, as Carnot did. [And] so?

The Initiate-Continue-Revoice (ICR) pattern is repeated by the teacher to involve different students (see Figure 1). As Matteo was charged with recapitulating a common narrative about the efficiency of an ideal Carnot's engine, each of the other students were supposed to take on systematizing a part of the collective 
narrative about thermodynamics. For example, the following excerpt shows how the teacher moved from Matteo to another student, Giulio:

Teacher: Therefore also in the ideal, reversible cycles the efficiency is less than one. This fact, Giulio, that the efficiency is less than 1, also in reversible cycles... means that? I mean, what do we mean for reversible transformations?

The lack of silence in the transcript (see Figure 1) shows that all the students were ready to go on in the narrative and, hence, were closely following the previous interactions with the other students.

In her exchange with the researchers, the teacher commented on her teaching moves at this point in the discussion as follows:

The students have to be aware that physics has specific disciplinary constraints and they all have to recognize and respect these constraints. The students have to learn to build a long argument where each word and each sentence is dense in meaning [in Italian, the teacher used the expression "Each word is heavy as a stone"]

If we consider teacher-student-teacher interactions like the one reported above locally, ICR shows both its similarities and its differences with respect to the typical InitiateRespond-Evaluate (IRE) interaction. In ICR, like in IRE, there is normative knowledge and the students are requests to grapple with it. There are acceptable and non-acceptable responses that must be put in relation to "science" as defined by the scientific community. However, in IRE the teacher is the central locus of power and knowledge and, in this sense, the relation between teacher and student appears asymmetric 
(O'Connor \& Michaels, 2007). Moreover, the IRE sequence explicitly positions the teacher in an evaluating role. On the contrary, the triadic structure of ICR is a wheel of a long story and not a structure, like IRE, complete after the three turns of talk. Moreover, like in the Initiation-Response-Revoicing structure of O'Connor and Michaels, through revoicing the student is positioned as the holder of piece of knowledge, a noteworthy idea or explanation (O'Connor \& Michaels, 2007) and the ideological stance behind ICR is primarily Dialogic. Through ICR, the teacher shifts power to the collective level and locates it in the discipline itself with its shared norms.

This issue led us to anticipate another important aspect of how the teacher used ICR and that, we will argue, is fundamental in fostering appropriation. The act of revoicing is the locus where the teacher strategizes her interaction with individual students. As we will show in sections 6.2.1 and 6.2.2, the teacher used ICR differently with different students (while Matteo was guided to focus his reasoning on the formal relation of engine efficiency, Chiara was led to open the narrative and to move the accountability of knowledge to the class). This strategized interaction reinforces a Dialogic stance that remains behind ICR inasmuch as it contributes to fostering personal positioning with respect to physics and to the class. The intention behind such strategized moves is to both emotionally support and to encourage students as they take differentiated and idiosyncratic forms of ownership of their learning.

Because of the Dialogic stance of ICR, the participant framework behind "Tightening the Reins" is closer to the "teacher as mentor" (Tabak \& Baumgartner, 2004) than to "teacher as monitor." 
To sum up, our analysis uncovers the participant framework and the talk move ICR - that allow us to interpret Lesson A in interactional terms. Both the participant framework of teacher as monitor and ICR appear instrumental to the general scope of the lesson to generate, collectively, a share understanding, activated by teachers' initial requirement of "making her understand what they all have understood."

However, this elucidation of the features of interaction in this lesson alone does not significantly explain how the students could find their own voices. For this we needed to flesh out what participant frameworks were behind "Letting the Reins Loosen."

\subsubsection{Participant frameworks stimulated by "Letting the Reins Loosen"}

In contrast, Lesson B centered on a discussion of the epistemological texts the students had analyzed at the beginning of the unit. The nature of the questions and expected responses revolved around resolving issues of coherence between arguments and points of view. That is, the class was collectively exploring the quality of argumentation of an issue that could be viewed in multiple ways. The flow of discussion involved three distinct moments, corresponding to the requirements of the questions posed to students:

1) The first requirement was to articulate one's own view about possible criteria for distinguishing and comparing the macroscopic and microscopic perspectives, elaborating the narrative they had been building in epistemological terms. For example, the teacher opened the discussion with the following question: "We arrived at the end of our path on Thermodynamics and you have reflected about these macro and micro approaches. So, now we are asking you (all) to express your own point of view - in a calm way, calm, but 
express it. What difference do you see, now, between the two approaches?" Such a prompt required students to point out and share potential criteria for comparing the two different approaches to thermodynamics. The students were asked to provide their personal elaboration of the epistemological texts they had analyzed in the beginning of the unit through the written questionnaire and that were asked to re-read for the lesson. The map of this part of the lesson (fig. 2) shows that three students participated: Paolo, Chiara and Caterina. The long bars reveal that they took time to express their views, with the teacher interacting briefly with each of them. An example of interaction in this part of the discussion is the following:

Paolo: ... maybe also I would write (in the questionnaire) that intuition anyways is necessary for getting to the first principles, therefore about things from which ... we begin from anyways. They [the principles of macroscopic thermodynamics] are based on observations and from observations we need to have intuition for getting to some principles above all if we are constructing the theory.

Teacher: And does it seem to you that the same kind of intuition is necessary for getting to the other type of theory [the kinetic theory of gases]. They are the same kind of intuition or ...?

Paolo: (interrupting and anticipating the end of Teacher's question.) No, in my opinion it is different.

Teacher, While Paolo is finishing, adds: "In what sense?

Paolo: That is, (they are) almost opposed because perhaps in the theory of type B (macroscopic thermodynamics) I wrote that one observes a phenomenon 
empirically... That is, from empirical observation of a phenomenon one adds to the theory (the teacher shushes the background noise/buzz), instead intuition plays a role during the entire research process in theories of type A (the kinetic theory of gases/microscopic perspective on thermodynamics). Perhaps it (intuition) is the impulse that gives the initial push.

(a couple of seconds of pause)

Teacher: Impulse, how so?

Paolo: That is... perhaps... while in theories of type B (the macroscopic thermodynamics) we proceed by intuition ... Hmm... In theories of type A (the kinetic theory of gases) it's enough to have one initial intuition for formulating principles and after we proceed with another method.

In the previous excerpt, Paolo is focusing on the role of intuition and the teacher simply intervenes to help him to develop his idea as criterion to compare the two approaches. In addition to asking clarification questions (e.g., in what sense? how?), the teacher took on the role of keeping reasoning on task. When she asked the question "They are the same kind of intuition or ...?", she was positioning Paolo to take up the task of comparing the two approaches. The content authority in this excerpt is the student who chose the piece of knowledge he preferred to address the collective task of comparing the two approaches. The teacher did not judge or evaluate his personal choice. We thus argue that the role of the teacher in this excerpt is that of "supporter," which is positioned in between the "teacher as mentor" and "teacher as partner" participant frameworks 
discussed by Tabak and Baumgartner: she did not play the role of a peer, but she also did not act as disciplinary authority. She oriented the flow of argument by helping the students to make their thinking explicit and to keep their argument on task.

2) The second requirement was to analyze one's own claims about the criteria for comparing theories and test their robustness and inner consistency, by interpreting other authoritative (and perhaps puzzling) positions about the difference between the two approaches. This requirement was formalized by the following question from the teacher about the epistemological texts the students had reflected upon prior to class "Why did Einstein include Special Relativity among the theories of principles and classical mechanics among the constructive theories? Are your criteria for distinguishing between theories of principles and constructive theories consistent with Einstein?" This requirement implied each student needed to re-consider the personal criteria that they had begun articulating for distinguishing between the two types of theories and check if it could be robust enough to justify the distinction made by Einstein. The question posed by the teacher was very subtle and complicated because many criteria used by the students to distinguish the macroscopic and microscopic approaches resulted retaining classical mechanics as more similar to the macroscopic approach than to the microscopic approach to thermodynamics. The map of this part of the lesson (fig.3) shows that seven students tried to provide their contribution in this phase of the discussion.

Chiara, for example, initially made very explicit that she saw a similarity between classical mechanics and relativity. Her first contribution to this part of lesson B (see Figure 3) is the following: 
Chiara: (I put classical mechanics in the theories of principles because) in my opinion, his [Einstein's] speculations in some way come from the observation of reality. Therefore... in principle there is a theory of principles that is based on observation of reality and then this observation creates some axioms from which one can begin. But initially there is an observation.

After Chiara's contribution, the teacher re-opened the discussion, since it was clear that the criterion used by the student ("the role of observation") to describe the theory of principles did not fit with Einstein's position:

Teacher: Who the other time, now I don't remember, put it (classical mechanics) in constructive theories (a brief pause where everyone either raises their hands or they look). Here, Lorenzo, try to explain, because you put it in constructive theories [before]. Now would you still put it there?

Lorenzo: Me... Yes... I put it there because... there were some assumptions,... therefore let's say I thought that these initial assumptions, how he said his own thought, therefore I put it (classical mechanics) in constructive theories...

Teacher: And which of those hypotheses, in your opinion [warrant its placement with constructive theories]?

Lorenzo focused on the word "assumptions" and, as she wrote in her notes, the teacher thought it was a productive point to leverage. In order to help him to develop his intuition in a fruitful way, she introduced the term "hypotheses" as a sort of synonym of 
"assumptions." She most definitely wanted to orient him to focus his attention more explicitly on the productive expression in Einstein's text: "the starting point and foundation [of constructive theories] are hypothetical constituents [like the hypothesis of the molecular movement]" (Einstein, 1919). In this choice, the teacher revealed having a specific plan for how to guide the class in addressing a puzzlement that the questionnaire had surfaced earlier.

As map of Figure 2 shows, the teacher stays with Lorenzo for some time and the entire exchange is aimed at supporting him in developing his argument. For example:

Teacher: Which of those hypotheses according to you? (one can hear Lorenzo's voice which is soft and difficult to hear). For example, we juxtapose the micro approach and the theory of relativity. Constructive theories, according to Einstein, make assumptions. Therefore, the hypotheses that we make in the micro theory and the hypotheses that Einstein made - Lorenzo - for the theory of relativity, what kind of hypotheses are these?

Lorenzo: For thermodynamics it is the movement of molecules that...

Teacher: And therefore there are hypotheses that ...?

The previous discussion shows again an attempt by the teacher to leverage Lorenzo's conjecture and to guide him to resolve the issue. But Lorenzo got lost and was not able to take up the teacher's suggestions. Other students intervened, until Chiara again came into the discussion and finished the argument: Constructive theories are based on hypotheses about the constituents of matter and, hence, on models of the elementary objects (point masses). Unlike them, the theories of principles are grounded on general principles that 
act as constraints that other physical theories have to respect (like a conservation law or a principle of relativity) without making any hypotheses about the elementary constituents of matter. This exchange with Chiara is analyzed in section 6.2.2.

Here, we only stressed that, at the level of the class, the teacher played a stronger role than in the first part of the lesson. She knew where she wanted to lead the class and guided the students to focus their attention on key points of Einstein's argument. She however did not give the answer and close the sequence of this collective reasoning. She simply oriented the attention of the class by highlighting significant terms, and in particular, she stressed and stayed firm on the word "hypotheses" and asking questions about them. The students still had to construct a way to resolve the puzzlement. Even though the teacher was not using here IRF or ICR discourse patterns, the role of the teacher here appears to be that of a mentor. The teacher was purposeful and played the role of guiding the interaction because of her knowledge.

3) The third requirement of the discussion in Lesson B was to express a preference, choose an approach and defend one's own ideas by situating them with respect to other possible views expressed by their classmates. This requirement was formalized by this question: "What perspective (macro or micro) do you prefer? Which one is, in your opinion, more effective at getting at the core of a phenomenon? We had the impression that, in the class, there are different positions on this issue." This third requirement implied different students should compare their views with the views of classmates and, through the comparison, they would extend, develop and elaborate their thinking. 
As Figure 4 shows, the question given above fostered direct interactions among the students. The first student who participated was Michele who expressed his strong preference for the microscopic approach:

Michele: Because it [the microscopic approach] exactly goes to the heart of things, that is, really we say ... it really explains ... because for example the temperature speaking in macroscopic terms is a bit difficult to explain while in microscopic terms it is easier. So, for me it is more real.

Then, Matteo stressed his strong position against the microscopic approach because its foundations on hypothetical assumption made the theory less true than a theory based on empirical facts. Caterina joined in spontaneously to stress that in the discussion they were confusing "real" and "true," while the two concepts had to be taken apart:

Caterina: Prof., in my opinion we must distinguish between truth and reality, because if we want one thing we must distinguish between true and real because maybe there are real things that we can see empirically but that are not true because we believe in a constructive theory (in the sense that these facts are in contradiction to our theory), but in my opinion, to be truthful a theory should be also to be real and therefore ...

Caterina turned to the teacher as moderator of the discussion. The teacher indeed answered implicitly by allowing her to go on with her argument (the teacher specifically did not take up the bid for her to be involved in a way so as to decide "who was right"). When Caterina stopped talking, it was Matteo who took up and went on with his argument (the rhythm of this exchange between Matteo and Caterina can be easily 
recognized also in fig.4). Like in the "teacher as partner" framework, the students interact directly with each other and the exchanges are more symmetrical, fluid and ungoverned. In this last part of lesson B, the students felt very free to express their thoughts but the teacher, more than a peer, played the role of facilitator or moderator.

To sum up, in contrast with Lesson A, all the questions in lesson B were epistemological in nature. There were no right/wrong answers - the questions posed of students were genuine puzzlements. Here the authority was redistributed to the students (in parts 1 and 3) or on distinguished authors, like Einstein (in part 2).

Our analysis led us to infer that what the teacher described as "Letting the Reins Loosen" had an inner triadic structure and could be interpreted as a Elaborate- Analyze Situate (EAS) pattern. The EAS pattern was managed by the teacher as a sequence of open-ended questions that created a collective reflection where the students were invited to (1) find personal words to build criteria to compare difference approaches (Elaborate through an epistemological lens), (2) articulate the criteria and test their robustness and consistency against puzzling issues, as well as to characterize their special coherence (Analyze) and (3) express a preference and situate it against other possible positions of their classmates (Situate). In each part of E-A-S the teacher interacts with the students in a special way and enacts a different specific participant framework: first "teacher as supporter" for the individual verbalization, then "teacher as guide-mentor" to focus the collective attention and foster the development of consistent argumentation, and lastly "teacher as facilitator-mediator" in the dialogue between students.

Importantly however, though articulated in three phases of the discussion, it is only in the combination of the three requirements that EAS has an identity at the level of the 
class. The combined request of re-framing, analyzing and defending makes EAS emerge as a way to establish or to consolidate disciplinary norms that are completely different from the disciplinary norms supported by the most traditional teaching (again, represented by the teacher as monitor participant framework and by the repetition of IRE discourse pattern). The norms that EAS supports include (1) multiple perspectives on a physical phenomenon are possible and yield differing insights (as opposed to a unique perspective) (2) argumentation in physics requires maintaining inner consistency in one's argument (as opposed to solely accepting the authority of a disciplinary expert such as a teacher) (3) competence in physics involves finding and expressing personal views (as opposed to only right/wrong answers).

While the repetition of ICR in Lesson A allowed the teacher to involve the whole class in becoming acquainted with the inner constraints of physics in the co-construction of a scientifically grounded and robust narrative, the use of EAS in Lesson B allowed the teacher to illustrate, at the level of the class, important features of the practice of developing scientific argumentation: intuitions have to be elaborated into claims, claims must be checked for their inner consistency and robustness, and then they must be compared with other claims and defended against possible critiques.

In summary, from analyzing the two lessons through the lenses of participant frameworks and discourse structures, the original metaphor of the teacher of "tightening the reins tight and letting them loosen" was transformed into a combination of different participant frameworks, enacted by the teacher through specific teaching moves. The analysis allowed us to point out that this combination of participant structures and 
teaching moves enabled the teacher to set the stage to resolve the tension between accountability to the discipline and research for personal relevance (Kapon et al., 2018).

In the following section the findings of the second stage of analysis are reported, so as to show how the patterns acted at the level of particular students.

\subsection{Individual Level Analysis}

As we argued in our introduction to the construct of appropriation, individuals create personal meaning for pieces of knowledge through encountering others' discourse, negotiating and reconciling others' ways of understanding and then coming to use the constructs with one's own inflections and nuances. For this purpose, we carried out a second level of analysis that involved focusing on two students (Matteo and Chiara) who had already successfully found their own voice to talk about the concepts and terms of the thermodynamics unit. That is, they were already successful in organizing their learning according to an explicitly personal style. At the beginning of the discussion of each case, we will provide a brief profile of each student. For each case, the analysis then zooms in on the interactions that the student had in lesson A and B and discusses how the patterns of interaction managed by the teacher acted at the level of the students and what participant frameworks were induced by the requirements of the discussions.

\subsubsection{Matteo}

Matteo, the student we discussed in section 2 with the strong interest in philosophy, frequently tried in class discussions to evade the more technical and formal aspects of physics (Fantini, 2014). As the teacher stressed in her interview and in the research 
discussions, "Matteo does not typically like to engage in solving problems, especially when technical mathematics is required solve them. For this reason, he is not considered a disciplinary reference in the eyes of his classmates" (Fantini, 2014). Despite this, and because of his ability to master philosophical arguments and to seek out debates with other students whose interests were more aligned with physics, he still had a recognized intellectual position in the classroom community. For the teacher, "Matteo is a student who constantly needed to be kept close to the discipline."

In Figure 5, we zoom in on a particular moment in lesson A in which PF interacts with Matteo.

\begin{tabular}{|c|c|c|}
\hline Turn & Speaker & Transcript \\
\hline 1 & Teacher: & $\begin{array}{l}\text { We have seen that from here [from the second law] come } \\
\text { thermal machines and that the efficiency// }\end{array}$ \\
\hline 2 & Matteo: & $\begin{array}{l}\text { The efficiency in a cycle cannot be greater than } 1 \text {, but } \\
\text { (pause). However, this is also in an ideal cycle. }\end{array}$ \\
\hline 3 & Teacher: & $\begin{array}{l}\text { Good. It cannot be. (pause) We are considering an ideal } \\
\text { cycle, an ideal, reversible cycle as Carnot did. So? }\end{array}$ \\
\hline 4 & Matteo: & It [the efficiency] must necessarily be smaller than 1 \\
\hline 5 & Teacher: & Exactly. Smaller than 1, not higher and not even equal. \\
\hline 6 & Matteo: & Exactly, not even equal \\
\hline 7 & Teacher: & If it were equal (pause).Tell me, efficiency is equal to// \\
\hline 8 & Matteo: & Work is equal to work over heat absorbed. \\
\hline
\end{tabular}


Matteo is dictating on the blackboard):

$$
\left.\eta=\frac{W}{Q_{a b s}}=\frac{Q_{a b s}-Q_{\text {lost }}}{Q_{a b s}}<1\right)
$$

10

$$
\text { Matteo: }
$$

11

Teacher:

12 Matteo:
Heat absorbed minus heat lost

If the efficiency were 1 , which of these terms would be zero?

The heat lost (pause). And this is not possible.

Figure 5 - Excerpt from Lesson A (Matteo)

In the first turns in the above excerpt, we can see a typical ICR sequence. In turn 1 , the teacher initiates the exchange without posing an explicit question. She suspends her voice to check where Matteo is, expecting him to pick up the thread she has initiated. Matteo understands and continues the thread of reasoning she has initiated. Then, the teacher revoices Matteo's contribution following confirmation that his reasoning is correct. ("Good. It cannot be..."). The next phrase of the teacher is a further elaboration of her revoicing in with she presses on a small imprecision in what Matteo said and she slightly elaborates "An ideal cycle, an ideal, reversible, cycle" so as to signal that Matteo could be more precise in his description of the values the efficiency can take on. The teacher, through the expression "so" re-invites Matteo to go on. Matteo responds by immediately fixing the imprecision: "It [the efficiency] must necessarily be smaller than $1 . "$

In turn 5, the teacher's revoicing serves the purpose of underlining and reinforcing the student's contribution (Smaller than 1 means not higher and not even 
equal). In turn 6, it is Matteo that uses revoicing, in this case with the purpose of giving feedback that he is following what PF is saying. He is now well-positioned with respect to the issue he was pressed on by PF.

In this sequence, the teacher and Matteo are building a shared and precise claim: efficiency in ideal reversible engines must is "smaller than 1, not higher and not even equal." This is a turning point that illustrates the extent to which ICR can be ideologically Dialogic (O’Connor \& Michaels, 2007). From this moment on, the central locus of knowledge becomes Matteo as, from turn 7 to turn 10, the teacher changes her position from guide to scribe for writing the formal relation that Matteo is supposed to dictate ("Tell me, efficiency is equal to..."). Here, Matteo succeeds in taking ownership of the formal relation and grounding his argument in formalism.

Finally, in turn 10 he is encouraged to complete his reasoning and he shows he is able to provide a well-argued response. In turn 11, the teacher poses the first "knowninformation" kind of question in this excerpt: "If the efficiency were 1, which of these terms would be zero?". Matteo's answer "The heat lost ... and this is not possible" is important for our analysis since it shows he is well-positioned with respect to the chain of reasoning and how his argument is getting more and more grounded in the discipline. The answer is indeed composed of two parts. Through the first part ("The heat lost") Matteo answers the last question of the teacher. But it is significant that he goes on with the sentence "and this is not possible." This last expression refers to the main issue they are debating. It speaks to the difference between saying that "The efficiency in a cycle cannot be greater than 1" and saying that "It must necessarily be smaller than 1." What could 
look like only a slight terminological difference, instead relates to the very essence of the second principle of thermodynamics.

The teacher, in her notes on the transcript, wrote that she decided to involve Matteo for building this part of the global narrative, since she wanted to guide him to get acquainted with formalism and to use it, so as to be in tune with her expectations for how students would be able to use the second law of thermodynamics at the end of the unit. Moreover, she wrote, interactions like the one above are important for Matteo also on an emotional and social level since they could allow him to gain credibility in the eyes of his peers (and himself) with respect to the physics content of the unit. In this sense, the ICR sequence above is revealed to be much more than a simple evaluation strategy or a Monologic way to transmit knowledge and establish where power and knowledge is in the classroom. Instead, through a strategized revoicing move, the teacher guided Matteo in using mathematical formalism both as a tool for calculation, and also as an aid in the expression of a chain of argument.

Turning to Lesson $\mathrm{B}$, we see that the organization of that lesson provided more space for Matteo to draw upon his philosophical orientations. Matteo's contributions to the discussion are indeed quite extended, particularly in the third part (see Figure 4). In the turns referred to in Figure 4, Matteo has a debate with a classmate, Michele. The specific requirement of situating oneself with respect to an approach to the content, as the third part of the EAS pattern, posed by the teacher to the class, stimulated the reactions of Michele and Matteo. When the teacher asked: "What perspective (macro or micro) do you prefer? Which one is, in your opinion, more effective at getting at the core of a phenomenon?" she already knew that the point was divisive for some students. Indeed, 
she commented: "We had the impression that in the class there are different positions on this issue." As we already discussed in section 6.1.3, faced with such a requirement, Michele argued for a microscopic approach - like constructive theories -- because you can see more a sense of mechanism and how things work in them. Hence, Matteo had the opportunity to express his ideas by defending macroscopic approaches. His argument hinged upon the idea that he didn't like that one can just make basic assumptions to produce a model and proceed in theorizing from there, as is done in the microscopic approach. That is, he did not like that there are aspects of reality that are not captured in this approach because models depend on how people see and interpret the world. (As an implication, Matteo thus objects to the idea that constructive approaches can be closer to reality if they depend on the theorist's perspective). In the following segment of a turn (which continues for nearly 2 and a half minutes in its entirety), Matteo tries to make sense of the position Michele shared about constructive theories.

Matteo: Perhaps [I feel less comfortable] with constructive theory [e.g., a microscopic approach to thermodynamics, based on kinetic theory of gases] that is, the one based on the underlying assumptions ... on models that we make. It depends. The fact of whether it is true or not also comes from ourselves, how we understand truth.

That is, one [Michele] can think that some things are true that are not validated in reality. But maybe for them [Michele] it is however true because we as humans construct the world and what we see depends on how we think of the world and how we experience the world. 
Through EAS and, in particular, through the challenge launched by the requirement of positioning and defending one's own position, Matteo could explore his idiosyncratic "signature" orientation toward physics, by confronting his position directly with Michele's position. These conditions include: i) the formulation of a question that could foster a debate between the two students, and ii) the establishment of discussion norms that provide the students with the awareness that, in physics, multiple interests and tastes are possible and legitimate, including the "philosophical" orientation of Matteo and the "engineering" orientation of Michele, provided that disciplinary constraints and the inner consistency of a position are respected.

To sum up, we can see that in lesson A, the repeated use of ICR allowed the teacher to keep Matteo close to the goals of the lesson within a collective discussion strongly focused on the content. In Lesson B, the triadic structure of EAS that included "situate, defend and test your position" gave Matteo the space to engage in a debate and to develop his personal philosophical position.

\subsubsection{Chiara}

We now turn to a discussion of how the use of ICR and the scaffolding provided by EAS supported another student, Chiara. Chiara was a very able, curious and diligent student. She excelled in physics, as well as in other school subjects. Like Matteo, Chiara also succeeded in appropriating the material in the thermodynamics unit, according to the meaning of appropriation we operationalized (Levrini et al., 2015). However, her orientation toward learning and her positioning with respect to physics was different from Matteo's and reflected her personal style. In general, as the teacher stressed during her 
interview and the research discussions, "Chiara likes the intellectual challenge of figuring out the characteristic features of differing points of view and also how multiple points of view can be used to manage the complexity of the world." The didactical approach taken in the unit of viewing the same physics concept through contrasting perspectives (in this case, the macroscopic and microscopic perspectives on thermodynamics) was thus quite natural and pleasing to her. Unlike Matteo, the teacher said, "Chiara has no difficulty with the formal and more mathematical aspects of learning physics. Her peers recognize her as a deep and generous thinker and they take her contributions to discussions seriously." Because of her interest in understanding and aligning points of view, Chiara often took on the role of mediating between different students in class discussions in which debates and multiple perspectives emerged (Fantini, 2014).

In Figure 6, we zoom in on a segment of transcript from an interaction with the teacher from the beginning of lesson A (see Figure 1).

\begin{tabular}{lll}
\hline Turn & Speaker & Transcript \\
\hline 1 & Teacher: & {$[\ldots]$ Chiara, how would we express the second principle from a macroscopic point } \\
of view? And what does it mean? \\
Chiara: & It's not possible to have a cycle where the internal energy introduced as heat is \\
& completely transformed into work. Hence (pause) that is// \\
& That is// \\
& So, this is a counter-principle [she is using this expression to stress that the \\
& principle is unusual since it expresses the "impossibility" of having something,, \\
& there is an imbalance here. Before we had seen only equalities in the principles, but \\
& for the first time we see that there is an inequality. Indeed, we had a discussion \\
& connected to Maxwell and Boltzmann and//
\end{tabular}



have defined the second law in this way and we have treated it with a macroscopic approach. What does it mean that we've covered the second law of thermodynamics with a macroscopic approach?

6 Chiara: That is, we have treated phenomena... that is, [the macroscopic approach] provides a theory of principles. We went through phenomena, what we see... We did not stop and look at the micro level, at the particles, [The teacher and Chiara almost together] at the structure of matter.

$7 \quad$ Teacher: Why do we move from a macro to the micro approach?

$8 \quad$ Chiara:

In order to understand what is beneath (pause). There is no need to use mechanics... one uses mechanics in order to understand what's behind it [thermodynamic concepts and laws].

9 Teacher: Let's say, we need to interpret this law//

10 Chiara: [Almost overlapping] Yes to interpret

11 Teacher: To give an interpretation of a law we have seen -- phenomenological law.

Figure 6 -Excerpt from Lesson A (Chiara)

The teacher asks Chiara to open a line of reasoning aimed at including the entire class. The pronoun we in "how would we express" is significant from this point of view. In turn 2, Chiara presents the second law with words that she seems to borrow from a book or the teacher. After that, she pauses to search for new hints from the teacher about what is expected of her contribution. The teacher encourages her to continue her train of thought ("That is..."). In turn 4 Chiara moves her discourse to a more philosophical and interpretive level, by stressing a very sophisticated point that characterizes the second principle of thermodynamics. However, the teacher stops her ("Let's keep calm...") and leads Chiara back to the inequality she had mentioned and to discuss the approach they 
used so far to address the second principle: the macroscopic perspective. This first exchange (turns 1-5) involved just a few words, but it is important for understanding the dynamics of the interaction. Chiara, who had not yet understood how much she is allowed to diverge in her reasoning, wanted to demonstrate to the teacher that she has studied well and she tried to move forward in bringing in Maxwell and Boltzmann to the discussion. The teacher took her back to the point that the teacher had asked about, at the same time acknowledging her contribution. Chiara had stated the second principle well, but the teacher was pressing Chiara to address the entire classroom community (instead of only responding to the teacher to demonstrate her understanding). Indeed in turn 5, through both the teacher's use of verbs (changing from "you" to "us") and also her pause of a few seconds, she gave Chiara time to return to the original request (to give meaning to the second principle from a macroscopic point of view -- for the whole class). Chiara then understood and continued her response at a meta-disciplinary level. Indeed, in turn 6 she restarts the collective narrative ("We have...") and focuses on the distinction between phenomena (what we see) and particles at the structural level of matter for distinguishing between the macroscopic approach (a theory of principles, in the words of Einstein) and the microscopic one approach (a constructive theory). At the end of this turn, the teacher says, almost at the same time, the same words that Chiara is saying: "structure of matter." This convergence of the teachers' and Chiara's utterances (and where the teacher chose to go next in the discussion) is evidence of Chiara's successful repositioning of herself with respect to the argument and also with respect to the role she was playing in the class. In turn 7, the teacher shifts to the microscopic approach, the focus of the previous lessons and Chiara reacts immediately. However, the teacher intervenes to position Chiara with 
respect to the word "interpretation." Chiara, again, quickly grasps the issue. The exchange ends with the teacher who now revoices with the purpose of underlining an issue introduced by her (interpretation) but, at the same time, to reinforce a point stressed by Chiara in turn 6 (the concept of phenomenological law).

The tempo of this exchange is interesting. Both Chiara and the teacher seemed very confident in this "duet." That is, it was a way for the teacher to express her esteem for Chiara but, at the same time, it was functional to move the accountability of content mastery to the whole class. Re-voicing here was a way to clearly move the locus of knowledge to the class and, in this sense, ICR reveals a Dialogical stance (thus appearing here very different from IRE).

Turning now to Lesson B, in the first part of the lesson (Figure 2), when the teacher required students to articulate their positions, Chiara entered the discussion after about seven minutes. The discussion had started to languish and the teacher assigned to Chiara the role of mediator:

Chiara: "What can I say? When I reread it [the questionnaire]...I mean... maybe from the macro and micro perspectives. The other time [at the beginning of the unit] there were many things I had not understood. I picked up some things [since then]. Some things I had [before] taken a little lightly. In light of the macro and micro. Maybe I can also understand the constituents of matter [Chiara refers to constructive theory now]. When one says "you make assumptions about the hypothetical constituents of matter" and it also says "explain the hidden nature of the mechanism" [Chiara refers to phrases from the questionnaire.] One wants to 
understand, not only based on empirical experiments, but we try to understand what is behind [those empirical experiments].

At this point the teacher encouraged Chiara to explain her personal point of view:

Teacher: What would you say in light of the path referring to the distinction between macro and micro as you understand it?

Chiara: I can understand it better because we analyzed thermodynamics from both aspects, seeing the differences and similarities. We have two different points of view. It is perhaps more comprehensive to analyze a phenomenon from two points of view. Perhaps this path [unit] widened my view.

This exchange continued for about 3 minutes without pause until another student asked for the floor and the discussion moved on. Chiara explained her developing thinking in a strong voice, with the help of the teacher. Although the interaction pattern of Figure 2 is structurally very similar of the pattern of "tightening the reins" (Figure 1), the teacher's role here was completely different than in lesson A. That is, the purpose was not to drive a discourse that was in the mind of the teacher, but rather to help develop a discourse that was in the mind of the student. Indeed, Chiara here was able to express what we recognized, in the previous paper on appropriation (Levrini et al., 20015), as her idiosyncratic idea. In her final interview, we pointed out that she constantly repeated the words "to see," "view" and the expression "to understand means to see" was said explicitly by Chiara 3 times. ${ }^{4}$ This idea was expressed by the following:

\footnotetext{
4 The interview was full of the metaphor of "understanding as seeing" so we took this to be the idiosyncratic idea around which Chiara developed her discourse in the interview.
} 
Chiara: We have analyzed thermodynamics from both perspectives, looking at differences and similarities. I mean, we have two different points of view ... it can be more complete to try to analyze a phenomenon, or whatever is around us, from two different points of view rather than from one and therefore this teaching path widens what we've done. It widened my view. The interaction with the teacher in the re-framing phase of the EAS pattern allowed Chiara to make it explicit to the class, and to herself, an idiosyncratic aspect that strongly characterized her voice.

Chiara intervened again after about 26 minutes into the lesson in the second part of the lesson during the analysis phase triggered by the question of why classical mechanics is, according to Einstein, placed in "constructive theories" and relativity is placed in "theories of principles" (Figure 3). As we have already anticipated, when Chiara entered into the discussion, the class was focused on the fact that one student was trying to argue why, in his opinion, Einstein considered the theory of classical mechanics a constructive theory and not a theory of principles. This explanation proceeded in an uncertain way, and was interrupted by short pauses and silences.

After a pause of a few seconds, Chiara intervened.

Chiara: While he [another student] was talking, I was thinking...I did not get to the answer in general. For thermodynamics it's fine, but for classical mechanics, I did not understand.

The student who was speaking turned to Chiara then tries to explain his point of view, but, once again, without being able to argue his position in a fluid and convincing way. 
Student: In my opinion, one [classical mechanics] is a theory of principles. But wanting to put it among the constructive theories - if you want to put ... it could be that of ideal experiments. To try to treat it, however, in my opinion is part of the theory of principles.

Chiara took the floor again in this interaction (now with a peer), to try to find new arguments to reinforce the point of view not only of her companion, but also hers.

Chiara: I mean, without taking anything away from Einstein, I would put it in the Theory of Principles. However, because that is ... it's not necessary as an underlying assumption, ...

I see my body that, if it is subject to a force, will have an acceleration and speed, and I understand the principle of it but I do not see the underlying assumption ....

Teacher: Assumptions of what type? What is it that you don't see? (You can hear the voice of Chiara in the background). Take up again that point, what is it that you don't see? What kind of assumptions do you not see?

Chiara: Eh, the hypotheses about how matter is made because so much in the end I considered it [matter] already as a point mass...

Teacher: Eh, maybe the point (Einstein's point) is just there.

Teacher: yes (comments of satisfaction in the background).

It is interesting to note that by her own reasoning, in her own words, Chiara realized that her belief (Classical Mechanics as Theory of Principles) could be revised. In the excerpt above Chiara externalized a personal dialogue with Einstein where, at the beginning, she acknowledged his authority and re-states their opposite positions: "I mean, without taking anything away from Einstein, I would put it in the Theory of Principles." The argument 
she uses refers to one criterion, among many others, that Einstein used in his writings for distinguishing theories of principles and constructive theories. The criterion was that a theory of principle, like macroscopic thermodynamics and unlike the kinetic theory of gases - that he considered the main example of constructive theory -, does not make any assumption about the constituents of matter. Chiara, at the beginning, used this argument to re-state that she considers classical mechanics a theory of principles since she does not see in this theory underlying assumptions about the basic constituents of matter: "because that is ... it's not necessary as an underlying assumption, ... I see my body that, if it is subject to a force, will have an acceleration and speed, and I understand the principle of it but I do not see the underlying assumptions .....". At this point the teacher invites Chiara to stop and make this point clearer, since she has come to focus her attention on the crucial issue and she just needed to recognize it. Chiara immediately understood the point: "eh..." This "eh" is the turning point in the special dialogue with Einstein. Here Chiara recognizes that the model of point mass can be seen as an assumption underlying classical mechanics and this can justify Einstein's argument of considering it as a constructive theory. As Bakhtin would say, Chiara developed her reasoning borrowing the words of Einstein ("the underlying assumptions on the constituents of matter") and, like in a productive case of appropriation a la Bakhtin, she tried to explore this phrase by populating it with her sense (Bakhtin, 1981).

In this moment of Lesson $\mathrm{B}$, once more Chiara is interpreting very precisely the intentions of the teacher and the sense of her puzzling and open-ended question: the teacher, to encourage students to develop their arguments and search for their inner consistency, introduced a puzzlement, an inconsistency dilemma through an important 
external voice. Such a move played the role of enlarging the polyphony and fostered a dialogic dynamics (Bakhtin, 1981). Chiara, even though she recognized Einstein's authority, didn't borrow his words passively but used them dialogically to develop and reinforce her personal view: She is making that process of transforming an apparently authoritative discourse into an internally persuasive one.

As in the case of Matteo, in lesson A, using ICR allowed the teacher to keep Chiara close to the content goals of the lesson, while in Lesson B, she gave Chiara the space to engage in a dialogical dynamics and develop her personal position, by systematically playing the role of mediator between the teacher and the class or between a student and the rest of the group. In particular, she was able to catch the profound sense of teacher's question and included Einstein's voice as part of the classroom dialogue.

\section{Comparing the cases of Matteo and Chiara}

The comparison of the cases of Matteo and Chiara demonstrates a particular point that we feel is worth stressing. In Lesson A, where the general goal of the teacher was to keep the entire class tuned in co-constructing a common, strictly disciplinary, discourse, the teacher found the way to interact with the students individually, yet in very different ways. Chiara was asked (and supported in) opening the generation of the shared narrative and giving it the tone and the accent that the teacher considered fruitful for making the whole discussion continue. Matteo was encouraged to face and overcome his main weaknesses with respect to creating and using mathematical formalism in argumentation.

In Lesson B, the comparison of Matteo and Chiara shows how EAS acts at the level of individual students. EAS is a collective, macro pattern of interaction that 
involves a multiplicity of participant frameworks. The variety of requests (e.g., Elaborate, Analyze, and Situate) provides significant epistemological scaffolding and induces the activation of different attitudes and strategies toward the search for a personal voice. In the cases discussed, Matteo was particularly stimulated by the "Situate" request since for him the direct debate with another student was a useful opportunity for exploring his developing personal view. Chiara instead found the request of "Analyzing" more congenial since her personal view is rooted in the desirability of comparing multiple voices, characterizing their coherence and resolving their inconsistencies.

\section{Discussion}

In this paper we focused on empirically grounding and analyzing a specific metaphor tirare e mollare la corda ("tightening and loosening the reins") used by the teacher to describe how she managed the tension between creating a collective disciplinary narrative at the level of an entire class and encouraging students to position themselves personally with respect to that narrative. This tension appears instrumental in supporting a particular kind of learning, termed appropriation, that encompasses both the mastery of disciplinary content as well as situating one's learning in wide and personal projects of intellectual and emotional growth.

The first stage in our analysis was to recognize interactional structures involved in enacting the teacher's metaphor across two lessons. Through further stages of analysis, we discovered that behind the metaphor was a complex epistemological scaffolding that the teacher enacted across the two lessons. This scaffolding was articulated across four moments of discussion, each with a different function and purpose. 
These moments, considered together, lead us to identify a macro pattern of interaction that captures both the disciplinary constraints articulated in Lesson A and the room for interpretation and personal positioning fostered by Lesson B. We name this macro pattern of interaction SEAS, because of the initials of the four functions it includes:

1. Sharing the construction of a collective disciplinary narrative;

2. Elaborating the narrative in epistemological terms by articulating criteria for comparing different approaches to the disciplinary content;

3. Analyzing the comparison criteria to test and characterize their coherence and inner consistency;

4. Situating oneself with respect to different approaches to the content informed by the refined criteria.

The first function (Sharing the construction of a collective disciplinary narrative) was implemented by the teacher in Lesson A, through chains of ICR sequences that involved different students. This function was enacted to guide the students in becoming acquainted with the constraints of physics and collectively building a disciplinarygrounded and robust narrative of what they had learned so far. While "tightening the reins" involved the entire class working together on a collective process of knowledge building, through the articulated forms of revoicing involved in ICR, the teacher interacted in quite an individualized and subtle manner with individual students, so as to nurture their self-efficacy with respect to the discipline and their positioning within the class.

The combination of the other three functions of SEAS, that is, ElaboratingAnalyzing-Situating (EAS), was implemented by the teacher in lesson B through a 
sequence of open-ended questions that shifted disciplinary authority to the students and provided the epistemological infrastructure for students to develop and test their personal "signature" ideas in reference to the content they were studying. In particular, while the function "Sharing the construction of a disciplinary narrative" guided the class in getting acquainted with the constraints of physics, EAS fostered the creation of a polyphony of voices and a dialogical dynamic that, according to Bakhtin's view of appropriation, allowed individuals to confront the tension between authoritative and internally persuasive discourses (Tabak \& Baumgartner, 2004). In so doing, students could borrow words from others (students, teachers, disciplinary references like Einstein), populate them with their own meanings, and situate them with respect to other possible meanings.

In each part of EAS the teacher's role shifted, inducing different participant frameworks. The first part of the discussion could be characterized in terms of "teacher as supporter" where the teacher's role was to support the students to search for and articulate their personal ideas for reframing the material of the unit through the lens of the epistemological tools from the questionnaire. Next, the participant framework shifted to "teacher as mentor," where her role involved focusing collective attention and fostering students' development of thick and consistent argumentation. Lastly, the participant framework shifted to "teacher as facilitator" in which her role involved facilitating classroom social interactions and dialogue that occurred primarily between students as they shared and defended their personal perspectives (after positioning with respect to different possible approaches). .

The four functions of the discussions (SEAS) appear to promote appropriation, as defined and operationalized in Levrini and colleagues, 2015. Indeed, the elaboration of a 
signature idea, its application to ground one's personal view in the discipline, the ability of developing a non-incidental (repeated across the activities) and epistemologically thick argument to be used in social interactions are the features of students' discourse we found in the final interviews and that we argued characterize the result of a process of appropriation (Levrini et al., 2015). Through the analysis reported in this paper, we could unpack where and how the four functions of SEAS contributed to activate these the development of these abilities that we recognized in students' discourse.

We now discuss how the teacher's enactment of the four functions of the discussions is linked to the design principles for the unit. The design principle of multiperspectiveness provided students some understanding and experience to draw upon when they were asked to apply epistemological vocabulary concerning different types of theories and models in order to compare the two perspectives on thermodynamics they studied. The function of "elaborating the narrative in epistemological terms" is linked to the design principle of multi-dimensionality. Finally, the principle of longitudinality ensured that students were positioned to be able to look back across their experience with physics to test out the comparative criteria they were generating against other example theories they had studied (e.g., classical mechanics and special relativity). This multiplicity of examples was a key resource in arguing for and defending their personal positions.

\section{Conclusions}

The analyses reported in this paper all draw upon the contribution of the teacher who helped to make important features of her teaching practice explicit to us. In so doing, 
some features also became explicit to her. Reflective practitioners are a wonderful source of classroom practices, yet, even if they are aware of productive practices, they may not be articulated in such a way as to elucidate key features and how they operate. Schoenfeld's $(2002,2008)$ study of an experienced mathematics teacher orchestrating classroom discussions showed that what may have seemed "improvisatory" in the teacher's orchestration of the discussion to a casual observer, in fact, was a complex and regular pattern that was part of her professional repertoire and deeply related to her ideas about students, learning, and content (mathematics). While the teacher was consciously aware of certain aspects of her decision making in orchestrating classroom discussions, Schoenfeld's analysis revealed aspects that were not explicitly articulated and therefore the analysis led to a deeper understanding of the nature of how she led class discussions. In our study, the teacher shared with us the metaphor that guided her way of thinking of the issue of supporting individual learning processes within a collective learning process. Her metaphor "pulling the reins and letting them loosen" was something she felt was important in supporting students in appropriating the material in her classes. However, this broad metaphor was neither empirically grounded nor operationalized in a way that made her or others conscious of key features of her instructional approach. Thus, our analysis aimed to operationalize and empirically ground this metaphor and to investigate how her approach to orchestrating classroom discussions functioned with respect to students' appropriation of physics concepts. The explicitness of the analytic process we used and the transformation of the metaphor into a lens for interpreting empirical data are expected to do significant work to improve classroom teaching and to foster disciplinary authenticity and personal relevance in 
school science (Levrini et al., 2017). The analysis in the current paper, together with our previous paper on appropriation, can be an existence proof for how it is possible to foster a special kind of engagement that resolves a tension (that we often face in science education) between accountability to the discipline and fostering students' agency and authority (Authors et al., 2018). In part, due to the teaching materials and the classroom norms established by the teacher through her strategized orchestration of SEAS, students could be exposed both to science discourse and experiences that were authentic and relevant from a personal point of view.

In spite of the results we achieved so far toward unpacking what appropriation is and what kinds of classroom interactions can foster it, the complexity of classroom realities makes building a humble theory (diSessa \& Cobb, 2004) about how, when, and why appropriation occurs quite challenging. While identifying how SEAS supported appropriation is a significant step in understanding potential conditions for fostering deep and meaningful learning of disciplinary content, many questions remain about other possible means for supporting appropriation. For example, we recognize that aspects of this case are quite special. To name a few of the distinguishing characteristics of this case: the students had worked with this particular teacher over an extended period of time, the students themselves had more opportunities to immerse themselves in scientific content because of the organization of their type of high school (a liceo scientifico), and finally, the curriculum itself was innovative with the teacher a part of a design team that collaborated with the physics education group of the university. Furthermore, the topic in which we investigated the phenomenon of appropriation was explored with students at the end of their high school experience after they already had significant exposure to 
many concepts in physics and had developed metacognitive tools for reflecting on their study of scientific theories and relating them to each other.

Despite the specific characteristics of the case we have analyzed, we conjecture that SEAS may be found to be useful in a wide range of instructional contexts, not merely in contexts that share all of the features of this case. Identifying the structure and use of SEAS allows this conjecture to be explored in future work. Future work is needed also in order to understand how these conditions relate to other possible conditions under which appropriation may occur. Nonetheless, beginning to understand the nature of classroom discussions and the role a teacher can play in fostering appropriation is a good initial focus for the larger goal of understanding the conditions under which appropriation occurs. The analysis of this paper showed that the specific combination of constraints and degrees of freedom illustrated in the interactional patterns behind the metaphor of "pulling the reins tight and letting them loosen" did enable physics (in this case, the study of thermodynamics) to be a context for both disciplinary learning and a search for personal relevance and meaning. Thus, our analysis allowed us to unpack a case of "reversing the aesthetic flow" in which students' sense of relevance and meaning was situated within the discipline itself. The implications of this program of work are, we hope, the promotion of a greater affiliation by students with disciplines such as physics and developing students' image of physics as a discipline that can be highly personal and creative.

\section{References}


Bakhtin, M. (1981). Discourse in the novel (M. Holquist \& C. Emerson, Trans.). In M. Holquist (Ed.), The dialogic imagination (pp. 259-422). Austin: University of Texas Press.

Bartolini Bussi, M.G. (1995). Analysis of Classroom Interaction Discourse from a Vygotskian Perspective. In L. Meira and D. Carraher (eds), Proceedings of the 19th International Conference for the Psychology of Mathematics Education, Vol. 1, Universidade Federal de Pernambuco, Brazil, pp. 95-98.

Boero, P., Pedemonte, B. and Robotti, E. (1997). Approaching theoretical knowledge through voices and echoes: a Vygotskian perspective, Proceedings of the XXI International Conference for the Psychology of Mathematics Education, Vol. 2, Lahti (Finland), pp. 81-88.

Candela, A. (1999). Students' power in classroom discourse. Linguistics and Education, 10(2), 139-163.

Cazden, C. B. (2001). Classroom discourse: The language of learning and teaching (2nd ed.). Portsmouth, NH: Heinemann.

Delgatto, J. (2011). Applications of the Theories of Mikhail Bakhtin in Science Education, College of Education. Paper 1. http://via.library.depaul.edu/soe_etd/1. diSessa, A. A. \& Cobb, P. (2004). Ontological innovation and the role of theory in design experiments. The Journal of the Learning Sciences, 13(1), 77-103.

diSessa, A.A., Greeno, J. G., Michaels, S. \& O’Connor, C. (2016), Knowledge and Interaction in Clinical Interviewing: Revoicing. In diSessa, A.A., Levin, M., \& Brown, N.J.S. Knowledge and interaction: A synthetic agenda for the learning sciences. New York, NY: Routledge, pp. 348-376. 
Einstein, A. (1919, November 28). Time, space, and gravitation. Times (London).

Erickson, F. (1986). Culture difference and science education. The Urban Review, 18(2), $117-124$.

Fantini, P. (2014). Verso una teoria locale dell'appropriazione nell'insegnamento/apprendimento della fisica. PhD Thesis.

Forman, E. A., \& Ansell, E. (2002). Orchestrating the multiple voices and inscriptions of a mathematics classroom. Journal of the Learning Sciences, 11(2-3), 251-274.

Goffman, E. (1974). Frame analysis: An essay on the organization of experience. Harvard University Press.

Goffman, E. (1981). Forms of talk. University of Pennsylvania Press.

Hegedus, S. J., \& Penuel, W. R. (2008). Studying new forms of participation and identity in mathematics classrooms with integrated communication and representational infrastructures. Educational Studies in Mathematics, 68(2), 171-183.

Kapon, S., Laherto, A., \& Levrini, O. (2018). Disciplinary authenticity and personal relevance in school science. Science Education, https://doi.org/10.1002/sce.21458

Kattmann, U., Duit, R., Gropengießer, H. \& Komorek, M. (1996). Educational Reconstruction -bringing together issues of scientific clarification and students' conceptions. Paper presented at the Annual Meeting of NARST, St. Louis (MI), April 1996.

Kautz H., Heron P. R. L., Loverude M. E. \& McDermott L. C. (2005a). Student understanding of the ideal gas law, Part I: A macroscopic perspective, American Journal of Physics. 73, 1055-1063. 
Kautz H., Heron P. R. L., Shaffer P. S. \& McDermott L. C. (2005b). Student understanding of the ideal gas law, Part II: A microscopic perspective, American Journal of Physics. 73, 1064-1071.

Lampert, M. (1990). When the problem is not the question and the solution is not the answer: Mathematical knowing and teaching. American educational research journal, 27(1), 29-63.

Lemke, J. L. (1990). Talking science: Language, learning, and values. Ablex Publishing Corporation, 355 Chestnut Street, Norwood, NJ 07648 (hardback: ISBN-0-89391565-3; paperback: ISBN-0-89391-566-1).

Levin, M. (2018). Conceptual and Procedural Knowledge During Strategy Construction: A Complex Knowledge Systems Perspective. Cognition \& Istruction, DOI: $10.1080 / 07370008.2018 .1464003$

Levin, M., Levrini, O., Greeno, J. (2018). Unpacking the nexus between identity and conceptual change. In: (Eds.): Amin T.G.; Levrini O., Converging Perspectives on Conceptual Change. p. 305-312, London \& New York: Routlege, ISBN: 978-1$138-20539-0$

Levrini, O., Bertozzi, E., Gagliardi, M., Grimellini-Tomasini, N., Pecori, B., Tasquier, G., \& Galili, I. (2014b). Meeting the discipline-culture framework of physics knowledge: an experiment in Italian secondary school. Science \& Education, 23(9), $1701-1731$.

Levrini, O., diSessa, A. A. (2008). How students learn from multiple contexts and definitions: Proper time as a coordination class. Physical Review Special TopicsPhysics Education Research, 4, 010107-1-010107-18. 
Levrini, O., Fantini, P. (2013). Encountering Productive Forms of Complexity in Learning Modern Physics. Science \& Education, 22, p. 1895-1910.

Levrini, O., Fantini, P., Pecori, B., Tasquier, G. (2014a). Forms of productive complexity as criteria for educational reconstruction: the design of a teaching proposal on thermodynamics. Procedia - Social and Behavioral Sciences, 116, 1483-1490.

Levrini, o., Fantini, P., Tasquier, G., Pecori, M., \& Levin, M. (2015). Defining and operationalizing appropriation for science learning. Journal of the Learning Sciences, 24 (1), 93-136.

Levrini, O., Levin, M., Fantini, P. (2018). Personal, deeply affective, and aesthetic engagement with science content. In: (Eds.): Amin T.G.; Levrini O., Converging Perspectives on Conceptual Change. p. 305-312, London \& New York: Routlege, ISBN: 978-1-138-20539-0

Levrini, O., Tasquier, G., Branchetti, L., \& Barelli, E. (under review). Developing futurescaffolding skills through Science Education. Submitted to International Journal of Science Education.

Malgieri M., Onorato P., Valentini A., DeAmbrosis A. (2016). Improving the connection between the microscopic and macroscopic approaches to Thermodynamics in high school. Physics Education, 51(6):065010.

Mehan, H. (1979). Learning lessons: Social Organization in the Classroom. Harvard University Press. Cambridge, MA. new patterns of mathematical engagement by nondominant students. Unpublished doctoral dissertation, University of California, Berkeley. 
O'Connor, M. C., \& Michaels, S. (1996). Shifting participant frameworks: Orchestrating thinking practices in group discussion. In D. Hicks (Ed.), Discourse, learning, and schooling (pp. 63-103). New York: Cambridge University Press.

O'Connor, M. C., \& Michaels, S. (2007). When Is Dialogue ‘Dialogic'?. Human Development, 50, 275-285, DOI: 10.1159/000106415.

Osborne, J., Dillon, J. \& Nuffield Foundation. Science Education in Europe: Critical Reflections: A Report to the Nuffield Foundation.

Rogoff, B. (1995). Observing sociocultural activity on three planes: Participatory appropriation, guided participation and apprenticeship. In J.V. Wertsch, P. del Rio. and A. Alvarez (Eds.). Sociocultural studies of mind. Cambridge, England: Cambridge University Press, 139-164.

Rozier, S. \& Viennot, L. (1991). Students' reasoning in thermodynamics, International Journal of Science Education, 13, 159-170.

Russ, R., Sherin, B., \& Lee, V. (2016). The Intersection of Knowledge and Interaction: Challenges of Clinical Interviewing. In diSessa, A.A., Levin, M., \& Brown, N.J.S. Knowledge and interaction: A synthetic agenda for the learning sciences. New York, NY: Routledge, pp. 377-402.

Sayavedra, A. M. D. (2018). Reframing learning: How small shifts in teacher talk can support

Schoenfeld, A. H. (2002). A highly interactive discourse structure, in Jere Brophy (ed.) Social Constructivist Teaching: Affordances and Constraints (Advances in Research on Teaching, Volume 9), Emerald Group Publishing Limited, pp.131-169. 
Schoenfeld, A. H. (2008). Chapter 2: On Modeling Teachers' In-the-Moment Decision Making. Journal for Research in Mathematics Education. Monograph, 45-96.

Sinclair, N. (2001). The Aesthetic Is Relevant, For the Learning of Mathematics,21(1), 2532.

Stigler, J. W., \& Hiebert, J. (2009). The teaching gap: Best ideas from the world's teachers for improving education in the classroom. Simon and Schuster.

Tabak, I., \& Baumgartner, E. (2004). The teacher as partner: Exploring participant structures, symmetry, and identity work in scaffolding. Cognition and Instruction, 22(4), 393-429.

Tasquier, G., Levrini, O., Dillon, J. (2016). Exploring Students’ Epistemological Knowledge of Models and Modelling in Science: Results from a Teaching/Learning Experience on Climate Change. International Journal of Science education, 38 (4), 539-563.

Vygotsky, L. S. (1978). Mind in society: The development of higher psychological processes. (M. Cole, V. John-Steiner, S. Scribner, \& E. Souberman, Eds.). Cambridge, Massachusetts: Harvard University Press.

Wells, G. (2007). Semiotic Mediation, Dialogue and the Construction of Knowledge, Human Development, 50, 244-274, DOI: 10.1159/000106414 